\title{
A Study of Coordinated Vehicle Traction Control System Based on Optimal Slip Ratio Algorithm
}

\author{
Gang Liu ${ }^{1,2}$ and LiQiang Jin ${ }^{1}$ \\ ${ }^{1}$ State Key Laboratory of Automotive Simulation and Control, Jilin University, Changchun, Jilin 130025, China \\ ${ }^{2}$ Department of Automatic Control, Henan Institute of Technology, Xinxiang, Henan 453000, China \\ Correspondence should be addressed to LiQiang Jin; jinlq@jlu.edu.cn
}

Received 5 March 2016; Revised 31 May 2016; Accepted 21 June 2016

Academic Editor: Luis J. Yebra

Copyright (c) 2016 G. Liu and L. Jin. This is an open access article distributed under the Creative Commons Attribution License, which permits unrestricted use, distribution, and reproduction in any medium, provided the original work is properly cited.

\begin{abstract}
Under complicated situations, such as the low slippery road surface and split- $\mu$ road surface, traction control system is the key issue to improve the performance of vehicle acceleration and stability. In this paper, a novel control strategy with engine controller and active pressure controller is presented. First and foremost, an ideal vehicle model is proposed for simulation; then a method for the calculation of optimal slip ratio is also brought. Finally, the scheme of control method with engine controller and active brake controller is presented. From the results of simulation and road tests, it can be concluded that the acceleration performance and stability of a vehicle equipped with traction control system (TCS) can be improved.
\end{abstract}

\section{Introduction}

Vehicle traction control system plays an important role in electronic stability control (ESC) system. In order to improve the vehicle traction performance on low $\mu$ surface road and maximize the longitudinal friction coefficient, TCS is used to control the slip ratio within the range of optimal slip ratio by regulating engine output torque or braking pressure.

In recent years, many theoretical studies based on wheel slip rate are conducted all around the world. In literatures $[1,2]$, the logic threshold controller is realized by regulating the braking pressure. It is easy to implement this method, but the development cycles for different vehicles are long. Reference [3] introduces the throttle actuator system with the time delay scheme, and the vehicle test result shows the good performance for the TCS. In [4], the proportion integration differentiation (PID) controller is implemented to adjust slip ratio. Due to high nonlinearity of the vehicle dynamic system, these conventional linear controllers cannot meet the requirements of TCS under complicated road conditions. In [5], a fuzzy controller is proposed to control the driving wheel slip for robust traction control. The simulation indicates that the controllers can further maximize the traction force. Reference [6] introduces a coordinated cascade control strategy which includes two sliding mode controllers. Both the engine torque and the active brake pressure are tuned by sliding mode controllers. Reference [7] proposes a sliding mode observer for road adhesion coefficient estimation, and then the fuzzy controller is used to regulate the engine output torque by adjusting the fuel supply. The control strategy is implemented on Volvo 76 Turb. Reference [8] presents a model predictive control strategy for TCS. Reference [9] introduces a second-order sliding mode of TCS controller, and the TCS is coupled with a nonlinear observer to estimate the road condition.

From the researches mentioned above, we learn that there are two requirements for TCS controller algorithm. One is robustness. Wheel slip should be maintained at around target slip ratio under any complicated road surface conditions. The other one is that the TCS controller strategy should meet different demands in different road surface conditions. When the vehicle is accelerating on the low $\mu$ road surface, the stability should be considered as a key point. When it is driving on $\mu$ split (one driven wheel on the ice), the traction issue should be considered first. All of these references mentioned above are on single controller to regulate the slip ratio. However, the single controller cannot maintain the vehicle stability under complicated road conditions. It 


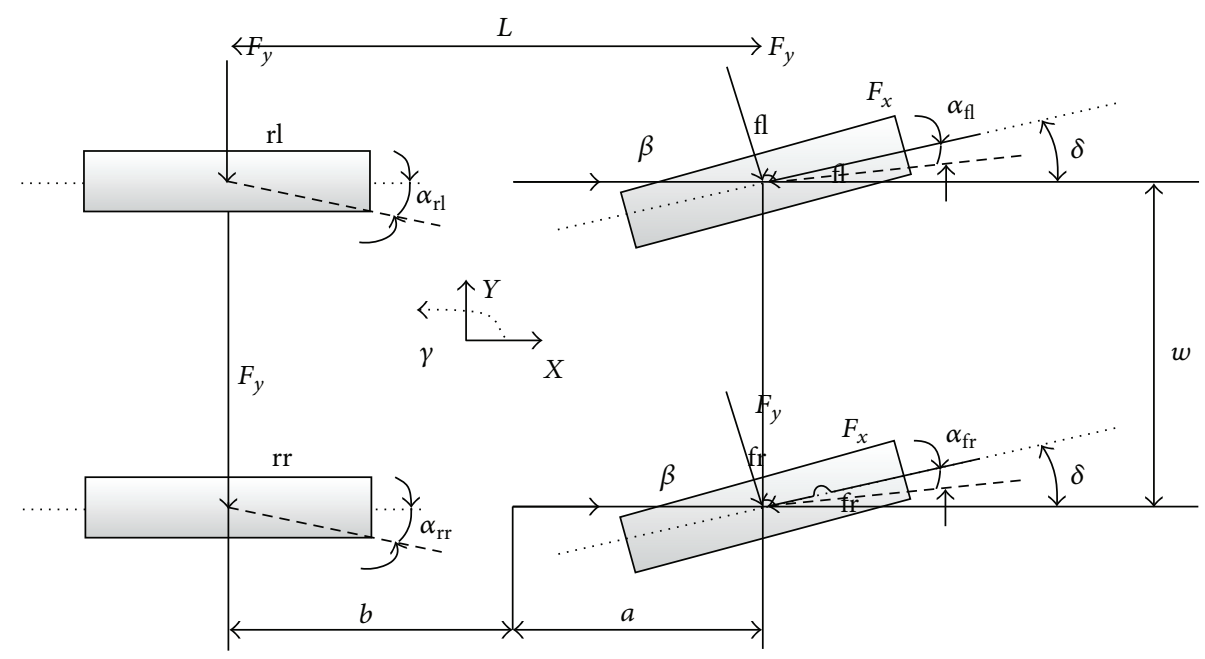

Figure 1: 7-DOF vehicle model.

is necessary to combine the active brake pressure controller with the engine torque controller. This paper presents a traction control system based on the engine output torque adjustment and brake pressure control. The optimal slip ratio is estimated via Varied Forgetting Factor Recursive Least Squares (VFFRLS). And the optimal slip ratio is considered as the desired value. The engine output torque is adjusted by fuzzy PID controller. The active brake pressure controller is based on sliding mode control theory. The control strategy is to coordinate these two controllers according to road surface conditions.

Section 2 introduces the vehicle dynamic model. Section 3 introduces the estimation algorithm of desired slip ratio. Section 4 explains the coordination strategy between the output torque and the brake pressure. Section 5 presents the results of simulation and the winter road experiments. Finally, conclusions are introduced in Section 6.

\section{Vehicle Model}

2.1. Vehicle Model. As shown in Figure 1, a nonlinear 7-DOF (degree of freedom) vehicle model is used to predict vehicle response under different road conditions during various driving maneuvers $[10,11]$. Some factors, such as the air drag resistance and the resistance of slope, are not considered. The vehicle model includes longitudinal motion, lateral motion, and yaw motion. The vehicle dynamic equations can be described as follows:

$$
\begin{aligned}
m\left(\dot{v}_{x}-v_{y} \dot{r}\right)= & \left(F_{x_{\mathrm{fl}}}+F_{x_{\mathrm{fr}}}\right) \cos \delta-\left(F_{y_{\mathrm{fl}}}+F_{y_{\mathrm{fr}}}\right) \sin \delta \\
& +F_{x_{\mathrm{rl}}}+F_{x_{\mathrm{rr}}}, \\
m\left(\dot{v}_{y}+v_{x} \dot{r}\right)= & \left(F_{x_{\mathrm{fl}}}+F_{x_{\mathrm{fr}}}\right) \sin \delta-\left(F_{y_{\mathrm{fl}}}+F_{y_{\mathrm{fr}}}\right) \cos \delta \\
& +F_{y_{\mathrm{rl}}}+F_{y_{\mathrm{rr}}},
\end{aligned}
$$

$$
\begin{aligned}
I_{v} \ddot{r}= & \left(F_{y_{\mathrm{fl}}}+F_{y_{\mathrm{fr}}}\right) a \cos \delta \\
& +\left(F_{y_{\mathrm{fl}}}-F_{y_{\mathrm{fr}}}\right) \frac{W}{2} \sin \delta \\
& -\left(F_{y_{\mathrm{fl}}}+F_{y_{\mathrm{fr}}}\right) b \\
& +\left(F_{x_{\mathrm{fl}}}+F_{x_{\mathrm{fr}}}\right) a \sin \delta \\
& -\left(F_{x_{\mathrm{fl}}}-F_{x_{\mathrm{fr}}}\right) \frac{W}{2} \cos \delta \\
& -\left(F_{x_{\mathrm{fl}}}-F_{x_{\mathrm{fr}}}\right) \frac{W}{2},
\end{aligned}
$$

where $v_{x}$ is the longitudinal velocity; $v_{y}$ is the lateral velocity; $r$ is the yaw angle; $\delta$ is the steer angle; $m$ represents the vehicle mass; $I_{v}$ is the yaw inertia moment; $F_{x}$ denotes the longitudinal forces of wheels; $F_{y}$ denotes the lateral forces of the wheels; $m$ is the vehicle mass; $a$ is the distance between front axle and center gravity; $b$ is the distance between rear axle and center gravity; $W$ is width of vehicle.

Wheel rotational equations can be expressed as

$$
I_{w} \frac{d w}{d t}=T_{q}-F_{d} r_{w}-T_{b}
$$

where $I_{w}$ denotes wheels inertia moment; $T_{q}$ is the longitudinal driving torque; $T_{b}$ is the breaking torque; $r_{w}$ is the wheel radius; $F_{d}$ is driving force between road and tire; $w$ is wheel speed.

The equations for each wheel can be described as

$$
\begin{aligned}
& F_{z_{\mathrm{fl}}}=F_{z_{\mathrm{fr}}}=\frac{m g}{2}\left[\frac{b}{L}-\frac{\left(\dot{v}_{x}-v_{y} \dot{r}\right) h_{g}}{g L}\right], \\
& F_{z_{\mathrm{rl}}}=F_{z_{\mathrm{rr}}}=\frac{m g}{2}\left[\frac{a}{L}+\frac{\left(\dot{v}_{x}-v_{y} \dot{r}\right) h_{g}}{g L}\right],
\end{aligned}
$$


TABLE 1: Values of the vehicle parameters.

\begin{tabular}{lc}
\hline Parameter & Value \\
\hline Vehicle mass & $1545 \mathrm{~m} / \mathrm{kg}$ \\
Gravity & $9.81 \mathrm{~m} / \mathrm{s}^{2}$ \\
$a$ & $1.14 \mathrm{~m}$ \\
$b$ & $1.63 \mathrm{~m}$ \\
Wheel radius & $0.32 \mathrm{~m}$ \\
Wheel width & $1.56 \mathrm{~m}$ \\
Height of center gravity & $0.52 \mathrm{~m}$ \\
Inertia moment & $2300 \mathrm{~kg} * \mathrm{~m}^{2}$ \\
Wheel inertia moment & $1 \mathrm{~kg} * \mathrm{~m}^{2}$ \\
\hline
\end{tabular}

where $F_{z}$ denotes the vertical force of each wheel; $h_{g}$ denotes the distance between the gravity center and the ground; $L$ is the distance between the front axle and the rear axle.

Other parameters of the vehicle model used for simulation are listed in Table 1.

2.2. Tire Model. Pacejka's tire model is used to simulate the contact forces between the road and the tire [12]. The equation of the tire longitudinal forces $F_{x}$ and $F_{y}$ can be defined as follows:

$$
y=D \sin \{C \arctan [B \lambda(1-E)+E \arctan B \lambda]\},
$$

where $B$ is the tire stiffness factor, $C$ represents the shape factor, $D$ represents the peak factor, $E$ represents the curvature factor, and $\lambda$ is the slip ratio, which can be expressed as follows:

$$
\lambda= \begin{cases}\frac{v_{x}-w r_{w}}{v_{x}} & \left(v_{x}>w r_{w}\right) \\ \frac{w r_{w}-v_{x}}{v_{x}} & \left(v_{x}<w r_{w}\right) .\end{cases}
$$

2.3. Engine Model. In this paper, the dynamics model of the engine can be depicted as

$$
T_{e}=T_{s}-f\left(\frac{d \alpha}{d x}\right)-J_{e} \frac{d \omega_{e}}{d t},
$$

where $T_{e}$ is engine output torque; $T_{s}$ denotes the static output torque of engine which is according to engine map chart; $d \alpha / d x$ denotes the function of the differential of throttle angle $\alpha ; \omega_{e}$ denotes the engine rotation speed; $J_{e}$ denotes crank's inertia moment. The engine output torque depended on the throttle angle and the engine speed of rotation.

\section{Parameter Estimation}

The precondition of slip ratio control is to estimate the optimal slip ratio exactly. The method of estimating the optimal slip ratio is based on seeking extreme value of $\mu$ - $\lambda$ curve $(\mu-\lambda$ curve denotes the relation between the road friction coefficient and the slip ratio). The relationship between $\mu$ and
TABLE 2: The values of Kiencke mode on different road conditions.

\begin{tabular}{lcc}
\hline Road condition & $p_{1}$ & $p_{2}$ \\
\hline Dry asphalt & 10.5104 & 34.5987 \\
Wet asphalt & 18.3410 & 58.4155 \\
Dry concrete & 11.2732 & 39.0633 \\
Dry cobblestone & 14.5401 & 6.2497 \\
Wet cobblestone & 58.2343 & 51.0124 \\
Snow & 118.3411 & 277.8144 \\
Ice & 536.0750 & 1010.8 \\
\hline
\end{tabular}

$\lambda$ can be expressed by Kiencke model [13]. The equation for Kiencke model is as follows:

$$
\mu(\lambda)=\frac{30 \lambda}{1+p_{1} \lambda+p_{2} \lambda^{2}},
$$

where $p_{1}$ and $p_{2}$ denote the parameters for different road conditions. Table 2 shows the values of $p_{1}$ and $p_{2}$ in different road surface conditions. Optimal slip ratio is available by seeking the extreme value of Kiencke model (8). Optimal slip ratio $\lambda_{p}$ is shown as follows:

$$
\begin{aligned}
\lambda_{p} & =p_{2}{ }^{-1 / 2}, \\
\mu_{p}\left(\lambda_{p}\right) & =\frac{30}{p_{1}+2 p_{2}{ }^{1 / 2}} .
\end{aligned}
$$

It is obvious that optimal slip ratio is available by determination of $p_{1}$ and $p_{2}$ on different road surfaces. Considering that the coefficients of friction $\mu(\lambda)$ and slip $\lambda$ are available instantly, $p_{1}$ and $p_{2}$ mentioned in (8) can thus be formulated by the Variable Forgetting Factors Recursive Least Square (VFFRLS) algorithm $[14,15]$ :

$$
y(k)=\Phi^{T}(k) \Theta(k),
$$

where $\Theta(k), \Phi^{T}(k)$, and $y(k)$ are given as

$$
\begin{aligned}
\Theta(k) & =\left[\begin{array}{ll}
p_{1}(k) & p_{2}(k)
\end{array}\right]^{T}, \\
y(k) & =30 \lambda(k)-\mu(k), \\
\Phi^{T}(k) & =\left[\begin{array}{ll}
\mu(k) \lambda(k) & \mu(k) \lambda^{2}(k)
\end{array}\right] .
\end{aligned}
$$

The recursive process of VFFRLS algorithm is shown as follows:

$$
\begin{aligned}
& \Theta(k)=\Theta(k-1)+G(k)\left[y(k)-\Phi^{T}(k) \Theta(k-1)\right], \\
& G(k)=\frac{p(k-1) \Phi(k)}{\Lambda+\Phi^{T}(k) p(k-1) \Phi(k)}, \\
& p(k)=\frac{1}{\Lambda}\left[I-G(k) \Phi^{T}(k)\right] p(k-1),
\end{aligned}
$$

where $I$ is the identity; $p(k)$ denotes the covariance matrix; $G(k)$ denotes the gain matrix; $\Lambda$ denotes the variable forgetting factor, which is in the range $(0.9,1)$. Seen from (11), the variable forgetting factor $\Lambda$ is directly related to the dynamic 


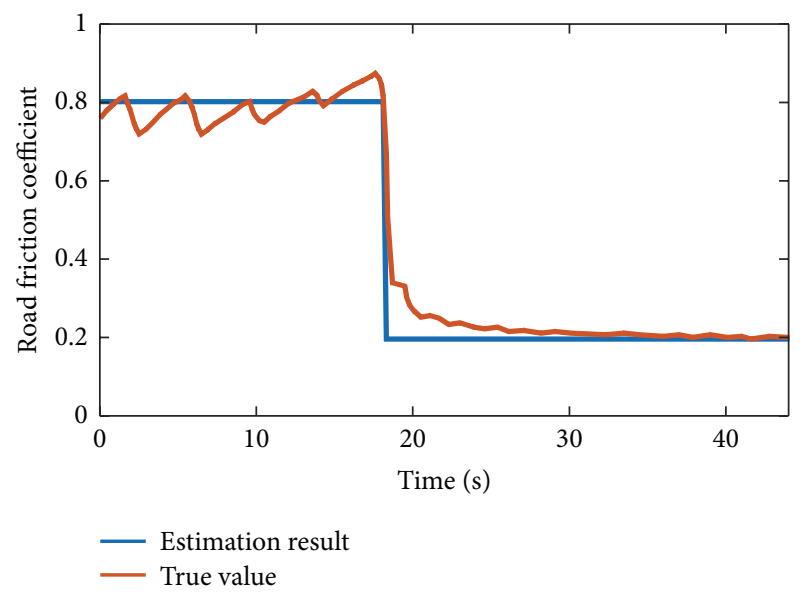

FIGURE 2: Simulation results of road friction coefficient.

tracking ability of Variable Forgetting Factors Recursive Least Square (VFFRLS) algorithm [16]. A low value of $\Lambda$ means the low weight of the past data. Owing to the different road conditions (i.e., varying- $\mu$ road), the value of $\Lambda$ is to decrease during road transient conditions and then restore back to its original value under steady state. The value of $\Lambda$ varies as follows:

$$
\Lambda= \begin{cases}\Lambda_{0} & U<|\varepsilon| \\ \Lambda_{1}+\left(\Lambda_{0}-\Lambda_{1}\right)(1-\exp (-\tau k)) & U>|\varepsilon|,\end{cases}
$$

where $\Lambda_{0}$ denotes the value of $\Lambda$ under steady state; $\tau$ denotes a sensitive coefficient which regulates the adjustment speed of forgetting factor; $\varepsilon$ denotes the differential equation of longitudinal acceleration.

Figure 2 is the simulation result of road friction coefficient estimation. The proposed method can estimate the coefficient quickly, and the error between the true value and the estimation value is less than 0.1 .

\section{Controller Design}

4.1. Control Scheme. The overall structure for TCS can be depicted as in Figure 3. When the driving vehicle accelerates on a complicated road surface, if the driving force of driving wheels exceeds the friction force, the wheel begins to skid. The TCS begins to estimate the optimal slip ratio. The value of optimal slip ratio is considered as the desired value of TCS. The engine torque controller and the brake torque controller are activated to adjust the output torque and the brake pressure.

Generally speaking, vehicles may get into acceleration trouble when driving on two typical road conditions. One is the low $\mu$ slippery road, and the other one is the split $\mu$ road surface. This paper proposes a control scheme to solve the traction problem by maintaining the slip ratio of wheels.

Under the low $\mu$ slippery road condition, engine torque controller is used to regulate the slip ratio of driving wheels. Under the split- $\mu$ road condition, the engine torque controller and the active brake controller are coordinately used to avoid

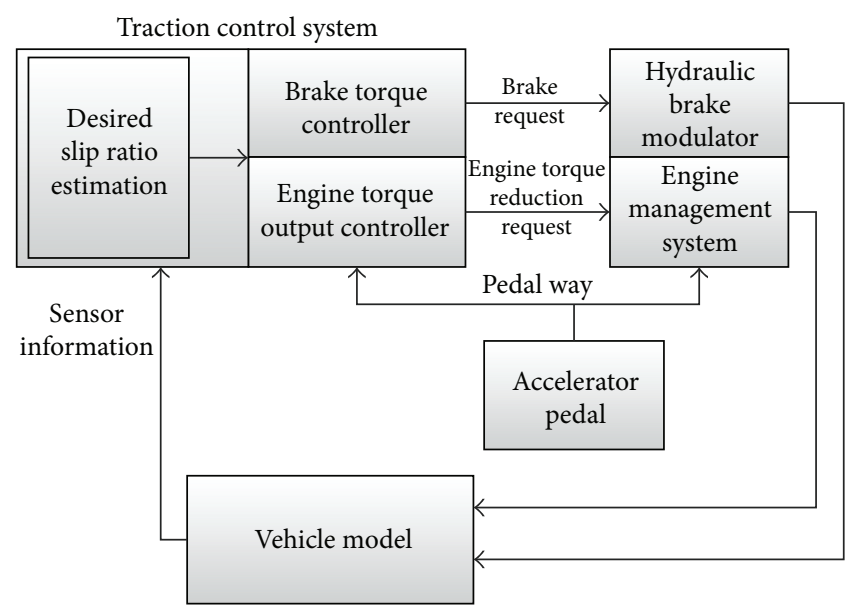

FIGURE 3: The structure of TCS.

the phenomenon of spin in two steps. In the first step, the active brake controller is used to regulate the slip ratio of driving wheels on the low $\mu$ road surface. The desired pressure can be calculated by the fuzzy controller. In the second step, the engine output torque is chosen to increase the output torque and the wheel angular acceleration. The engine output torque is calculated by the sliding mode controller.

4.2. Engine Output Torque Controller. As known to all, the throttle is used to adjust the output torque by regulating the amount of air. The adaptive sliding mode controller is chosen as the control algorithm of engine output torque. The error between the desired slip ratio and the current slip ratio can be defined as follows:

$$
e_{i}=\lambda_{i}-\lambda_{p}
$$

where $\lambda_{i}$ denote the current slip ratio; $\lambda_{p}$ is the desired slip ratio described in Section 3.

The sliding surface is as follows:

$$
s_{i}=\dot{e}_{i}+c e_{i}
$$

where $c$ is a constant and meets the Hurwitz theorem.

And the differential version of (14) is as follows:

$$
\dot{s}_{i}=\ddot{e}_{i}+c \dot{e}_{i}
$$

Then choose the control law:

$$
\dot{s}_{i}=\ddot{e}_{i}+c \dot{e}_{i}=-k_{0} s_{i}-\varepsilon_{0} \operatorname{sat}\left(\frac{s_{i}}{\phi}\right),
$$

where

$$
\operatorname{sat}\left(\frac{s_{i}}{\phi}\right)= \begin{cases}\frac{s_{i}}{\phi} & \left|\begin{array}{l}
\frac{s_{i}}{\phi} \\
\operatorname{sgn}\left(\frac{s_{i}}{\phi}\right)
\end{array}\right| \begin{array}{l}
\frac{s_{i}}{\phi}
\end{array} \mid>1 ;\end{cases}
$$

$\phi$ is the thickness about the boundary layer of the saturation function and the value of $\phi$ is greater than zero; $s_{i}=0$ can be 
achieved in finite time; both $k_{0}>0$ and $\varepsilon_{0}>0$ are the sliding coefficients, which can be tuned according to the effectiveness of control.

The differential version of (2) can be defined as

$$
I_{w} \ddot{w}=\dot{T}_{q}-\dot{F}_{d} r_{w} .
$$

Then based on (5), (18), and (16), the following formula can be deduced:

$$
\begin{aligned}
\ddot{w} & =-\left(c+k_{0}\right) \dot{w}+\frac{w}{v_{x}}\left(c \dot{v}_{x}+2 \dot{\lambda} \dot{w} r_{w}\right. \\
& -\varepsilon_{0} \operatorname{sat}\left(\frac{s_{i}}{\phi}\right) w r_{w}+k_{0} c v_{x}+k_{0} \dot{v}_{x}-k_{0} c w r_{w} \\
& \left.+k_{0} c w r_{w} \lambda_{p}\right) .
\end{aligned}
$$

Based on (18) and (19), the control torque can be deduced as

$$
\begin{aligned}
T_{q} & =\int I_{w}\left(-\left(c+k_{0}\right) \dot{w}+\frac{w}{v_{x}}\left(c \dot{v}_{x}+2 \dot{\lambda} \dot{w} r_{w}\right.\right. \\
& -\varepsilon_{0} \operatorname{sat}\left(\frac{s_{i}}{\phi}\right) w r_{w}+k_{0} c v_{x}+k_{0} \dot{v}_{x}-k_{0} c w r_{w} \\
& \left.\left.+k_{0} c w r_{w} \lambda_{p}\right)\right)+\dot{F}_{d} r_{w} .
\end{aligned}
$$

4.3. Active Brake Controller. As for the design of active brake controller, the fuzzy control algorithm is adopted to keep the slip ratio within the range of optimal slip ratio. There are two input signals and one output signal for fuzzy logic controller. One input signal is $e$ which denotes the error between the current slip ratio and the optimal slip ratio. The other one is $e c$ which represents the first derivative of $e$. The output signal of fuzzy logic controller regulates the opening of the solenoid valve by the PWM of ECU. Then the target brake pressure is available.

$e$ is divided into six fuzzy subsets: [NB, NM, Z, PS, PM, and $\mathrm{PB}$ ]; $e c$ is divided into seven fuzzy subsets: [NB, NM, NS, $Z$, PS, PM, and $P B]$; the output signal is divided into four fuzzy subsets: [NB, Z, PS, and PB].

As shown in Table 3, the rule base of active brake controller is based on the experience knowledge and expert knowledge. Then the gravity center method is used for defuzzification. If the output signal is zero, the brake pressure is in pressure-hold condition; if the output signal is $\mathrm{NB}$, the brake pressure is in pressure-increasing condition; if the output signal is $\mathrm{PB}$, the brake pressure is in pressuredecreasing condition.

\section{Experiment and Results}

5.1. Simulation Result. For validation, some typical simulations were carried out by using Matlab/Simulink software. The basic simulation conditions are listed as follows:

(i) Target path: straight, no steering angle input,

(ii) Accelerator pedal opening: $100 \%$.
TABLE 3: Table of fuzzy control rules.

\begin{tabular}{lccccccc}
\hline$e$ & & & & $e c$ & & & \\
& NB & NM & NS & Z & PS & PM & PB \\
\hline NB & PB & PB & PB & PS & PS & PS & PS \\
NM & PB & PB & PB & PS & PS & Z & Z \\
Z & PS & PS & PS & Z & NS & NS & NS \\
PS & PS & Z & Z & Z & NS & NS & NS \\
PM & NS & NB & NB & NB & NB & NB & NB \\
PB & NB & NB & NB & NB & NB & NB & NB \\
\hline
\end{tabular}

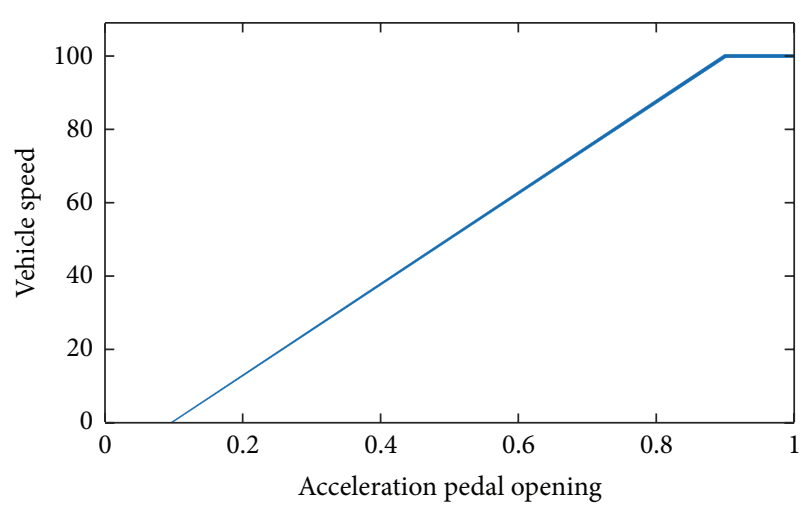

FIGURE 4: Control input.

Case 1 (low $\mu$ slippery road surface). Figure 4 shows the relation between the opening degree of accelerator pedal and the vehicle speed. The opening degree of accelerator pedal is proportional to the vehicle speed. However, the vehicle speed ceases to increase when the opening degree reaches $90 \%$.

Figure 5 shows the simulation result of the vehicle driving under a low $\mu$ slippery road surface condition. The friction coefficient of road surface is 0.2 . From Figures 5(a) and 5(b), from the comparison between the noncontrolled one and the controlled one, we can find that the speed of uncontrolled vehicle is $50 \mathrm{~km} / \mathrm{h}$ at $11 \mathrm{~s}$, but that of the controlled one is $50 \mathrm{~km} / \mathrm{h}$ at $7 \mathrm{~s}$. We can also find that there is about $45 \%$ improvement in the performance of longitudinal acceleration. From Figure 5(c), the one under control keeps the slip ratio within the range of optimal slip ratio (about 0.16). However, the driving wheels of the uncontrolled one slipped excessively.

Case 2 ( $\mu$-jump road surface). Figure 6 shows the simulation result of the vehicle driving under a $\mu$-jump road surface condition. The phenomenon of road transition from high $\mu$ $(\mu=0.8)$ to low $\mu(\mu=0.2)$ happens at $4 \mathrm{~s}$. From Figure 6(c), the slip ratio of uncontrolled one is soaring after $4 \mathrm{~s}$. It is obvious that the controller could identify the change of road conditions and the slip ratio is controlled to the new desired value.

5.2. Road Test Result. As shown in Figure 7, the TCS controller and a suite of standard sensors are added to the vehicle. The controller is a 32-bit microcontroller unit which 


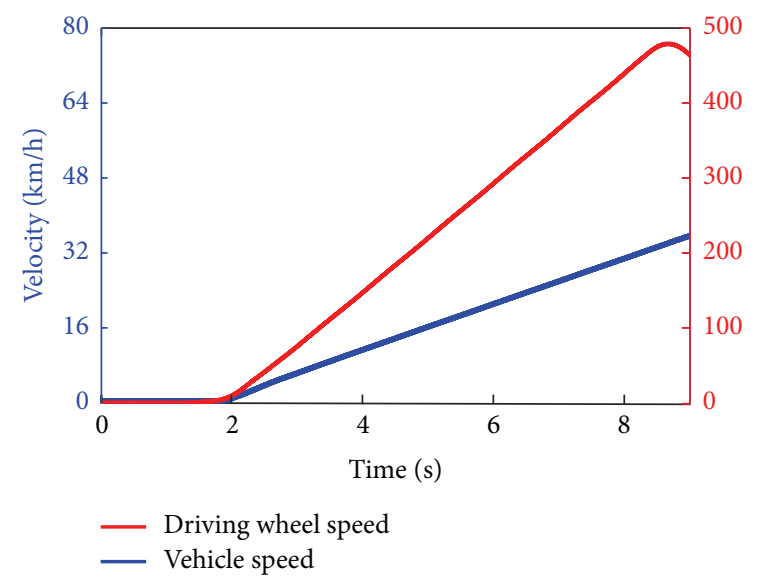

(a) Velocity versus time in Case 1 with no control

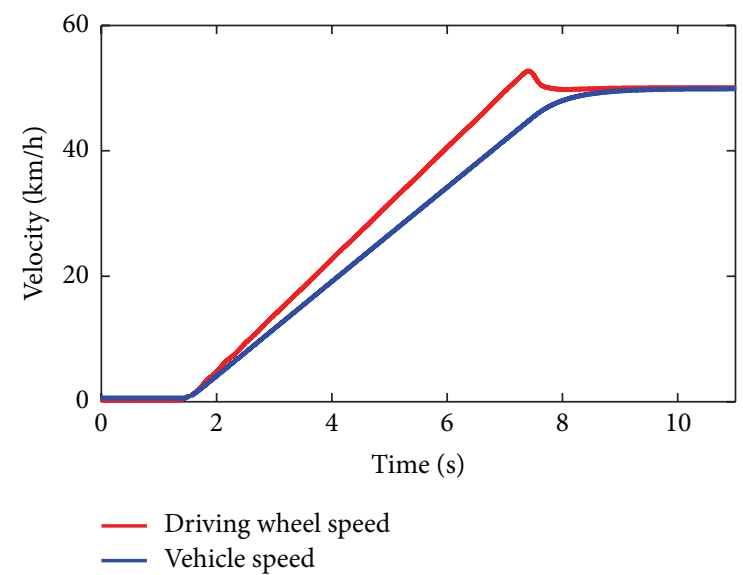

(b) Velocity versus time in Case 1 under control

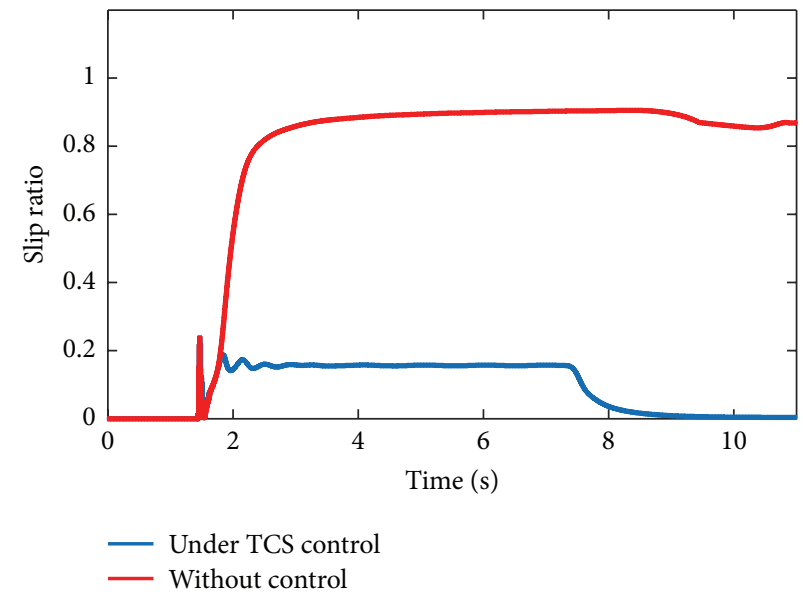

(c) Comparison of slip ratio between the one under control and the noncontrolled one

FIgURE 5: Simulation result of Case 1.

is produced by Freescale Semiconductor. The C code is obtained from the TCS control strategy of Simulink model; then $\mathrm{C}$ code is downloaded to microcontroller unit. And the microcontroller is mounted to the hydraulic unit. The testing system consists of Vector CANalyzer and a Speedbox. The CANalyzer captures sensory information and engine information from CAN bus. The Speedbox is used to measure the speed of the test vehicle.

Case 1 (ice road test). Figure 8 shows that the road test was carried out on an ice road. The friction coefficient of the ice road was approximately 0.2 . Figure 9 shows the test result of noncontrolled vehicle. The velocity of the vehicle was only $17 \mathrm{~km} / \mathrm{h}$ at the end of the road test. Furthermore, the slip ratio increased excessively.

Figure 10 shows the test result of the controlled one on the ice road surface. From Figure 10(a), the angular velocity of the driving wheel was reduced effectively by the engine output torque controller. The improvement of vehicle acceleration was $43 \%$. The gear changed at $12 \mathrm{~s}$. The optimal slip ratio was approximately 0.1 . Figure 10 (b) shows that the slip ratio was controlled within the range of 0.1. From Figure 10(c), when the vehicle began to accelerate at $2 \mathrm{~s}$, the current engine torque decreased quickly to the desired one. Then, the engine output torque followed the tendency of vehicle speed change. To conclude, the engine torque controller played an important role in restraining the slip ratio of the driving wheels on the icy road surface.

Case 2 (split- $\mu$ road test). Figure 11 shows the vehicle test on the split- $\mu$ road surface. The right side was ice $\operatorname{road}(\mu=$ 0.2 ), and the left side was dry concrete pavement ( $\mu=$ 0.8 ). Figure 12 shows the test results of parameters. From Figure 12(a), the angular velocity of the wheel on the slippery side was close to vehicle speed.

When the vehicle began to accelerate at $3 \mathrm{~s}$, the slip ratio of front right wheel increased excessively. Then the value was kept close to the desired slip ratio (approximately 0.1) as shown in Figure 12(b). From Figure 12(c), when the front right wheel began to skid at $3.2 \mathrm{~s}$, the engine torque controller reduced the torque quickly. Then the slip ratio was controlled by the brake pressure properly. To sum up, in the spilt- $\mu$ road 


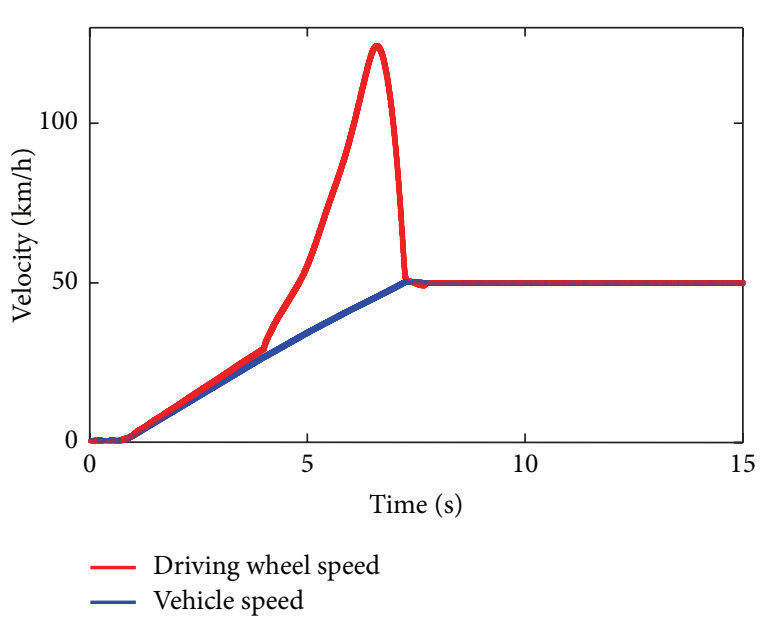

(a) Velocity versus time in Case 2 with no control

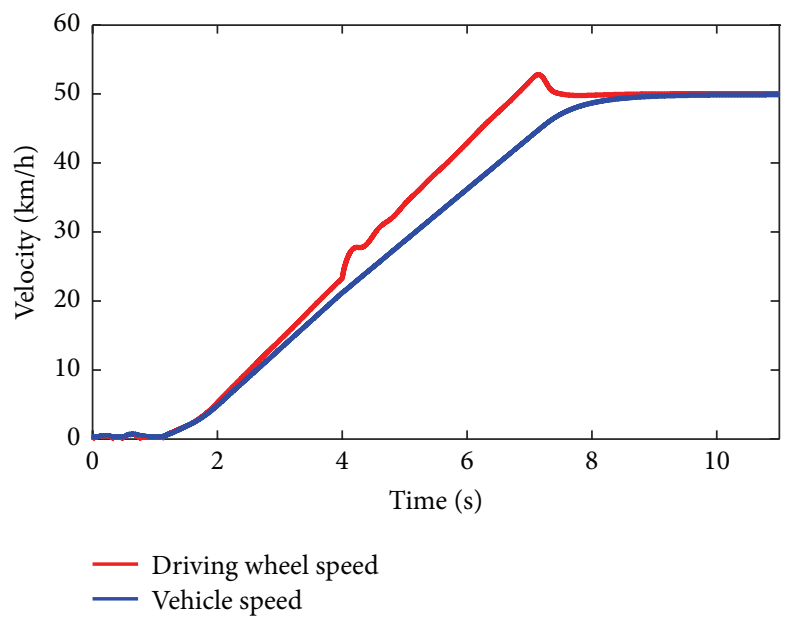

(b) Velocity versus time in Case 2 under control

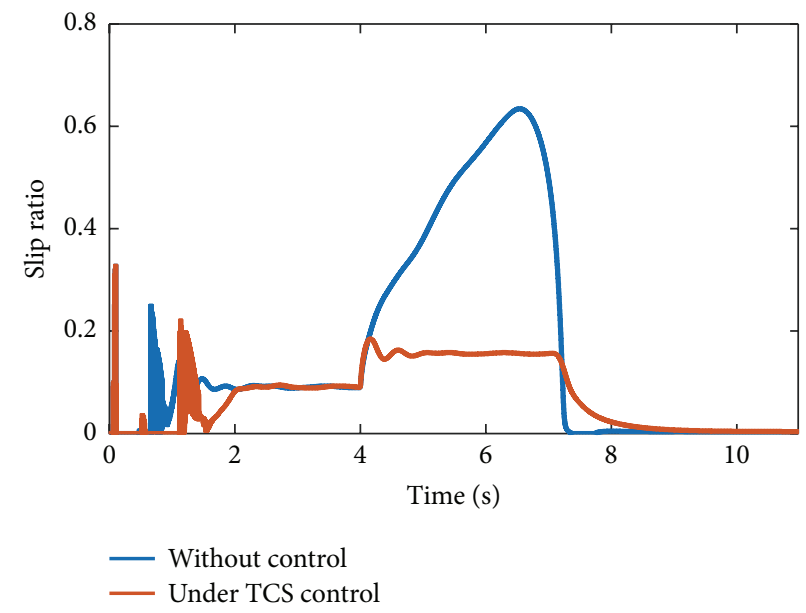

(c) Comparison of slip ratio between the one under control and the noncontrolled one

FIGURE 6: Simulation result of Case 2.

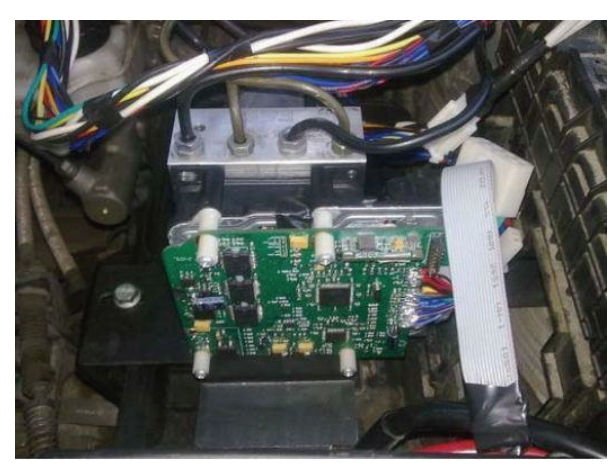

FIgURE 7: The MCU controller.

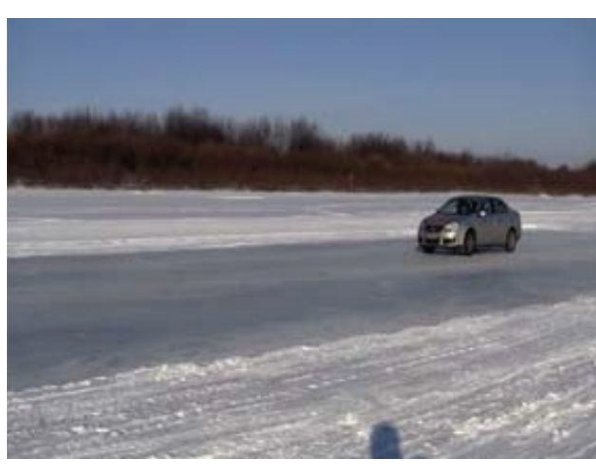

FIGURE 8: Winter test. test, the proper switch between the engine controller and the active pressure controller can improve the performance of acceleration and stability.

\section{Conclusions}

To sum up, this paper presents a novel traction control system, which consists of an engine torque controller and a 


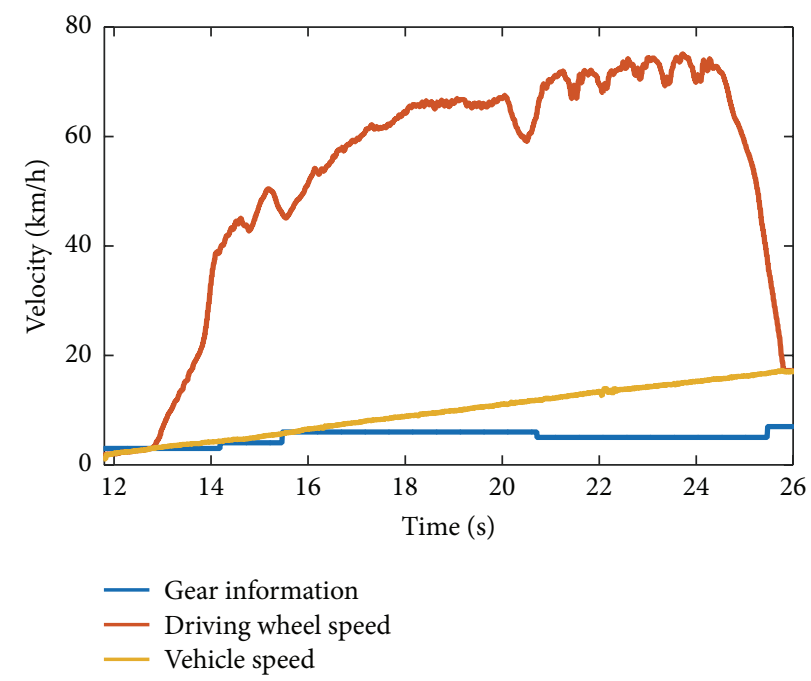

FIGURE 9: The winter test result with no TCS controller.

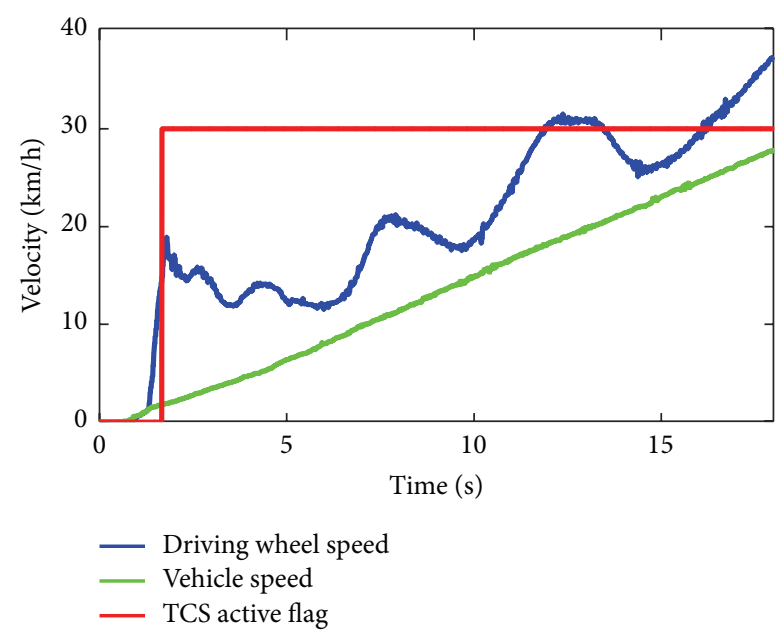

(a) Wheel speed versus vehicle speed

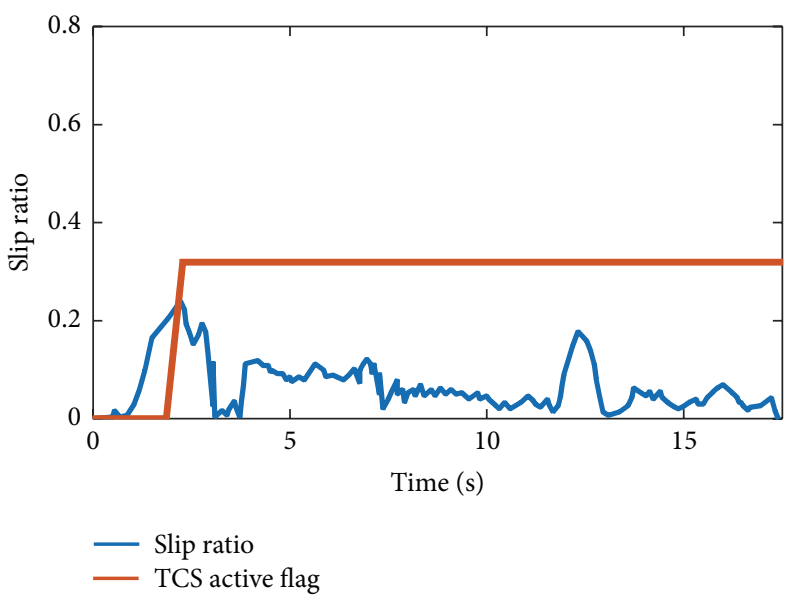

(b) Slip ratio

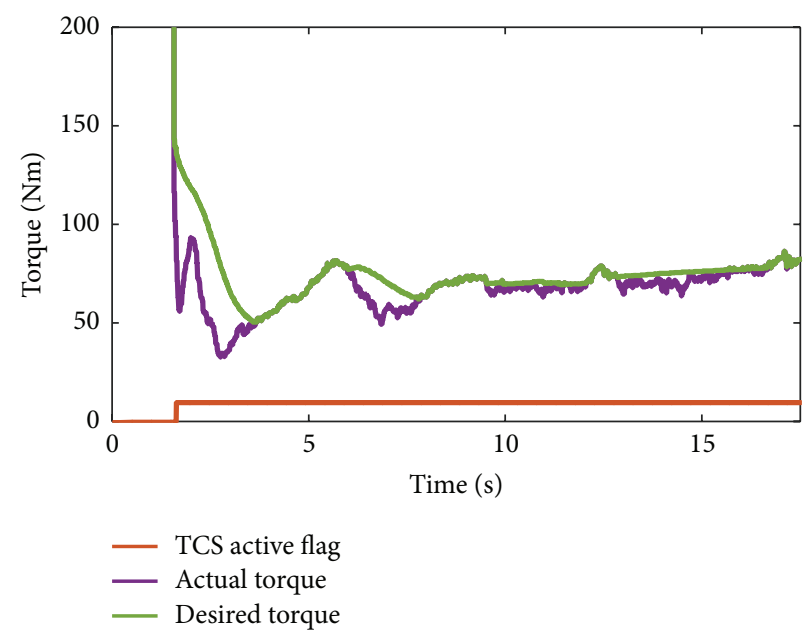

(c) Torque

FIGURE 10: The winter test results obtained on the ice road. 


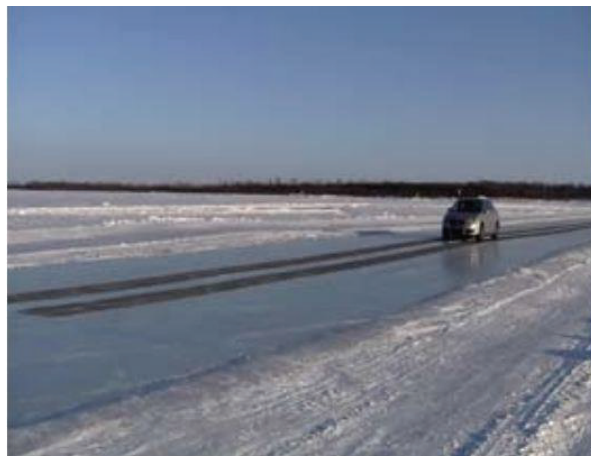

FIgure 11: The vehicle test under the split- $\mu$ road surface.

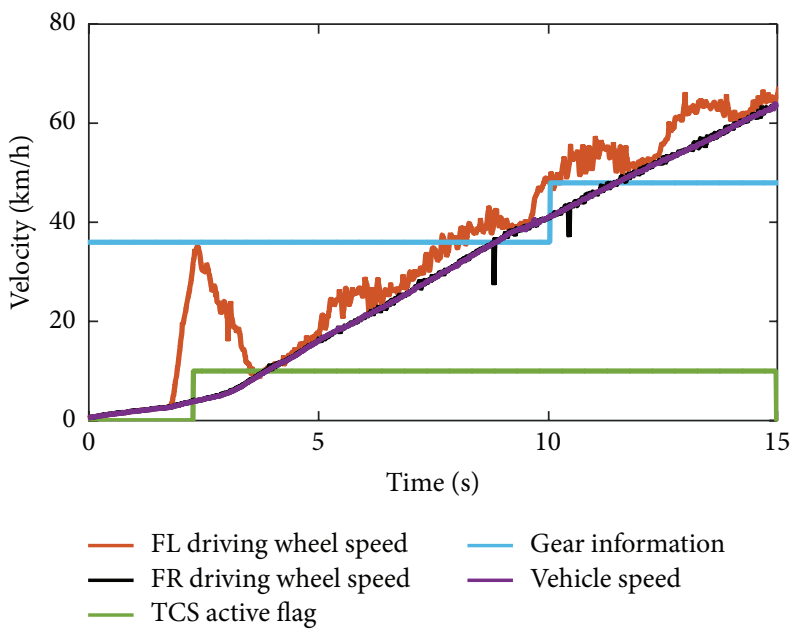

(a) Wheel speed versus vehicle speed

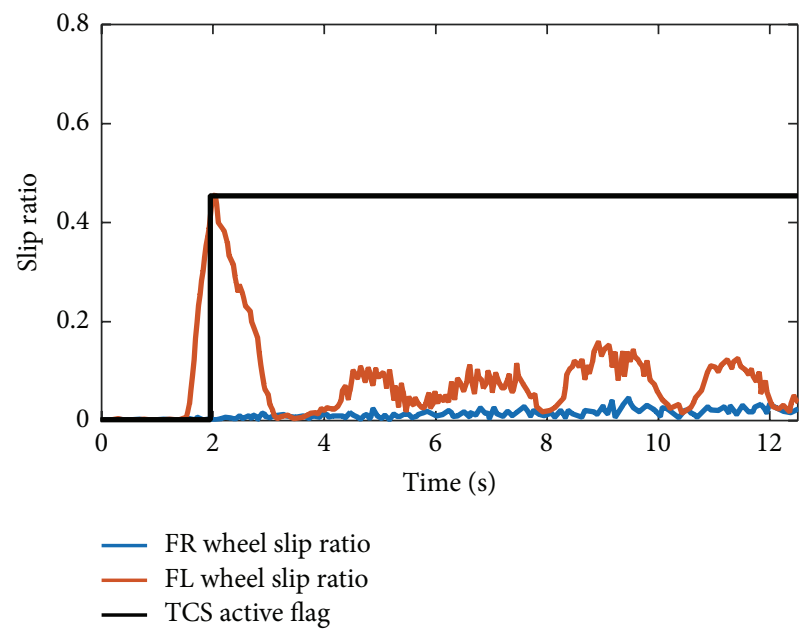

(b) Slip ratio

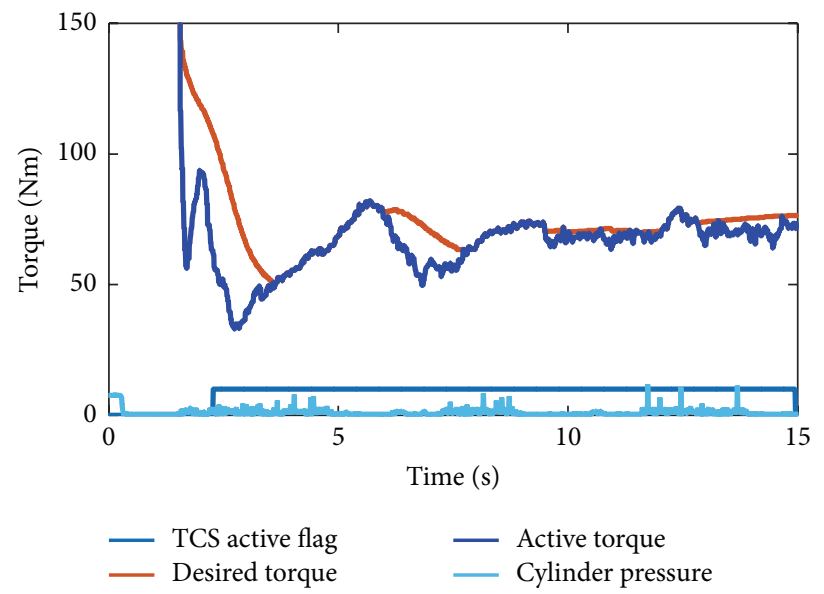

(c) Torque

FIgURE 12: The winter test results obtained on split- $\mu$ road surface.

pressure controller, for the evaluation of vehicle acceleration and stability. The characteristics of the TCS can be described as follows:

(1) A method for real-time calculation of optimal slip ratio is realized by Variable Forgetting Factors Recursive Least Square (VFFRLS) algorithm. And then the optimal slip ratio is considered as the desired value of slip control.

(2) The cascade control method with fuzzy control algorithm and sliding mode control algorithm can be effectively adapted to the complicated road surface conditions. 
(3) The algorithm takes $2 \mathrm{~ms}$ to run a time and runs once every $20 \mathrm{~ms}$, so that the TCS controller can discover and correct the vehicle wheel slipping phenomenon in time.

(4) Simulation, which is based on Matlab software, and typical road tests were carried out. The results indicate that the control scheme is fit for complicated working circumstances.

\section{Competing Interests}

The authors declare that they have no competing interests.

\section{Acknowledgments}

This work was supported by China Postdoctoral Science Foundation (2013M540248).

\section{References}

[1] A. T. Van Zanten, R. Erhardt, G. Pfaff, and F. Kost, "Control aspects of Bosch-VDC," in Proceedings of the 3rd International Symposium on Advanced Vehicle Control, pp. 573-607, Aachen, Germany, June 1996.

[2] H. Chen, X. Gong, Y.-F. Hu, Q.-F. Liu, B.-Z. Gao, and H.-Y. Guo, "Automotive control: the state of the art and perspective," Acta Automatica Sinica, vol. 39, no. 4, pp. 322-346, 2013.

[3] J.-B. Song and K.-S. Byun, "Throttle actuator control system for vehicle traction control," Mechatronics, vol. 9, no. 5, pp. 477-495, 1999.

[4] H.-Z. Li, L. Li, L. He et al., "PID plus fuzzy logic method for torque control in traction control system," International Journal of Automotive Technology, vol. 13, no. 3, pp. 441-450, 2012.

[5] G. Yin, S. Wang, and X. Jin, "Optimal slip ratio based fuzzy control of acceleration slip regulation for four-wheel independent driving electric vehicles," Mathematical Problems in Engineering, vol. 2013, Article ID 410864, 7 pages, 2013.

[6] M.-X. Kang, L. Li, H.-Z. Li, J. Song, and Z. Han, "Coordinated vehicle traction control based on engine torque and brake pressure under complicated road conditions," Vehicle System Dynamics, vol. 50, no. 9, pp. 1473-1494, 2012.

[7] J. H. Park and C. Y. Kim, "Wheel slip control in traction control system for vehicle stability," Vehicle System Dynamics, vol. 31, no. 4, pp. 263-278, 1999.

[8] F. Borrelli, A. Bemporad, M. Fodor, and D. Hrovat, "An MPC/hybrid system approach to traction control," IEEE Transactions on Control Systems Technology, vol. 14, no. 3, pp. 541-552, 2006.

[9] H. Lee and M. Tomizuka, "Adaptive vehicle traction force control for intelligent vehicle highway systems (IVHSs)," IEEE Transactions on Industrial Electronics, vol. 50, no. 1, pp. 37-47, 2003.

[10] Y.-J. Huang, T.-C. Kuo, and S.-H. Chang, "Adaptive slidingmode control for nonlinear systems with uncertain parameters," IEEE Transactions on Systems, Man, and Cybernetics, Part B: Cybernetics, vol. 38, no. 2, pp. 534-539, 2008.

[11] L. Li, J. Song, H. Wang, and C. Wu, "Fast estimation and compensation of the tyre force in real time control for vehicle dynamic stability control system," International Journal of Vehicle Design, vol. 48, no. 3-4, pp. 208-229, 2008.
[12] M. Amodeo, A. Ferrara, R. Terzaghi, and C. Vecchio, "Wheel slip control via second-order sliding-mode generation," IEEE Transactions on Intelligent Transportation Systems, vol. 11, no. 1, pp. 122-131, 2010.

[13] U. Kiencke, "Real-time estimation of adhesion. characteristic between tyres and road," in Proceeding of the IFAC World Congress, pp. 136-159, Sydney, Australia, 1993.

[14] K. Nam, S. Oh, H. Fujimoto, and Y. Hori, "Estimation of sideslip and roll angles of electric vehicles using lateral tire force sensors through RLS and kalman filter approaches," IEEE Transactions on Industrial Electronics, vol. 60, no. 3, pp. 988-1000, 2013.

[15] M. Doumiati, A. C. Victorino, A. Charara, and D. Lechner, "Onboard real-time estimation of vehicle lateral tire-road forces and sideslip angle," IEEE/ASME Transactions on Mechatronics, vol. 16, no. 4, pp. 601-614, 2011.

[16] C. Paleologu, J. Benesty, and S. Ciochiňa, "A robust variable forgetting factor recursive least-squares algorithm for system identification," IEEE Signal Processing Letters, vol. 15, no. 3, pp. 597-600, 2008. 


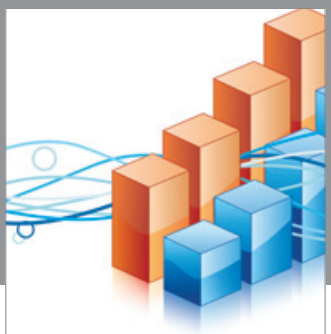

Advances in

Operations Research

vatem alat4

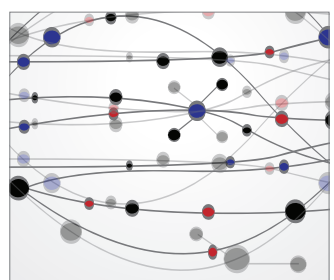

\section{The Scientific} World Journal
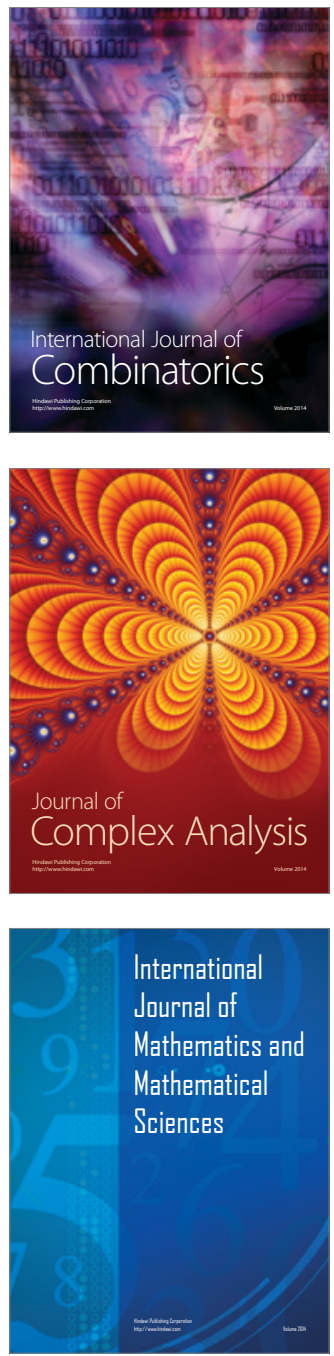
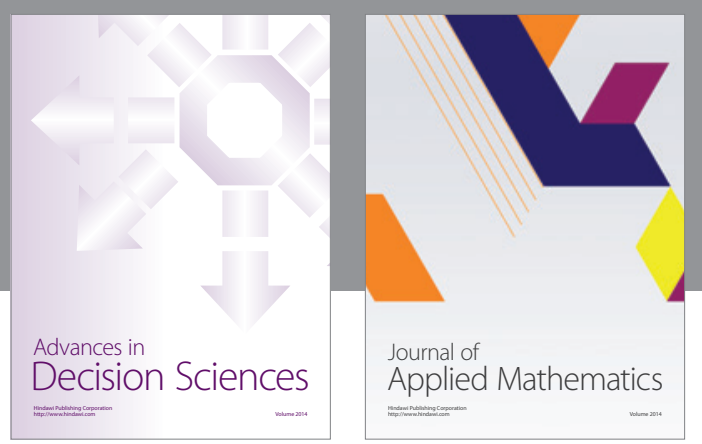

Algebra

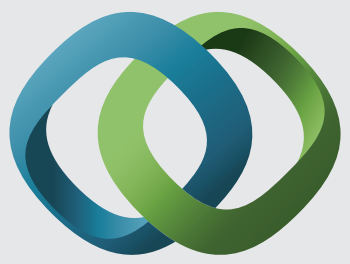

\section{Hindawi}

Submit your manuscripts at

http://www.hindawi.com
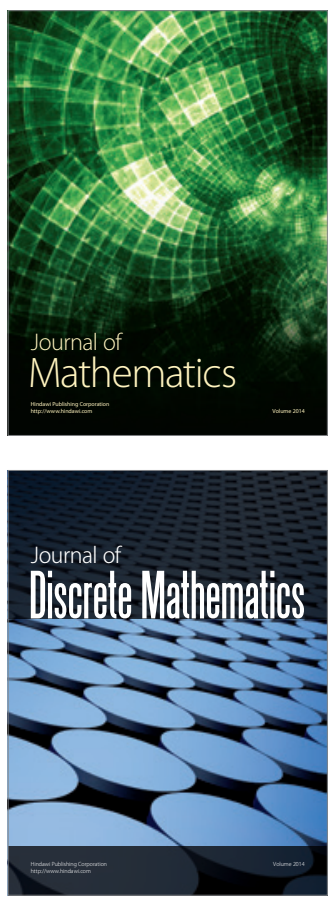

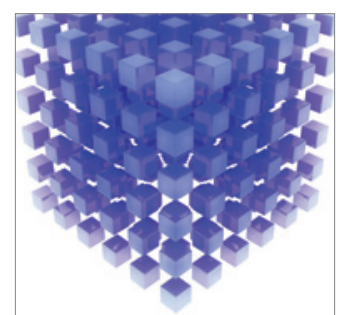

Mathematical Problems in Engineering
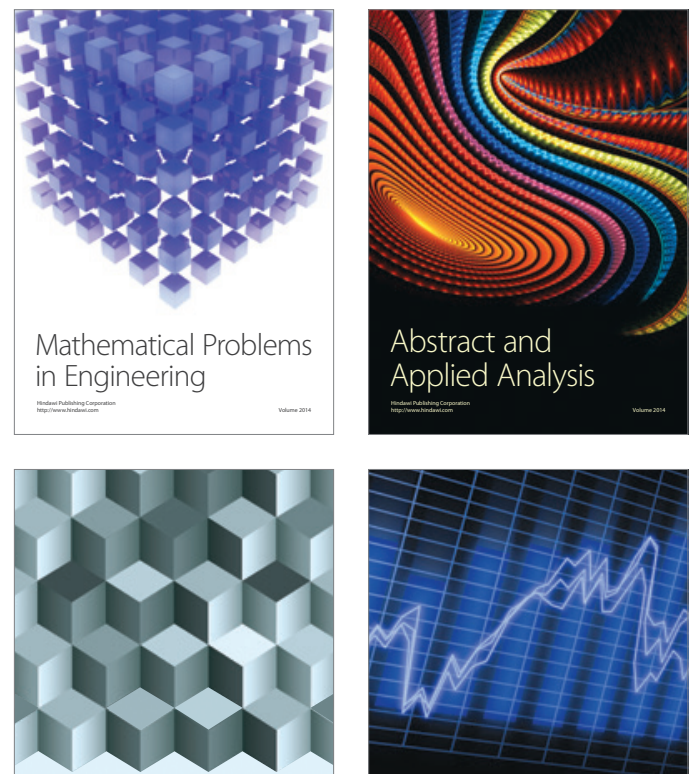

Journal of

Function Spaces

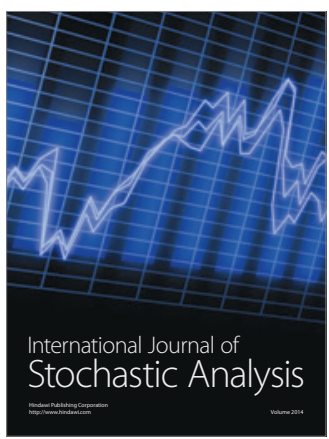

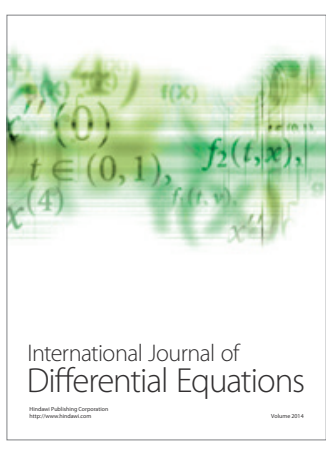
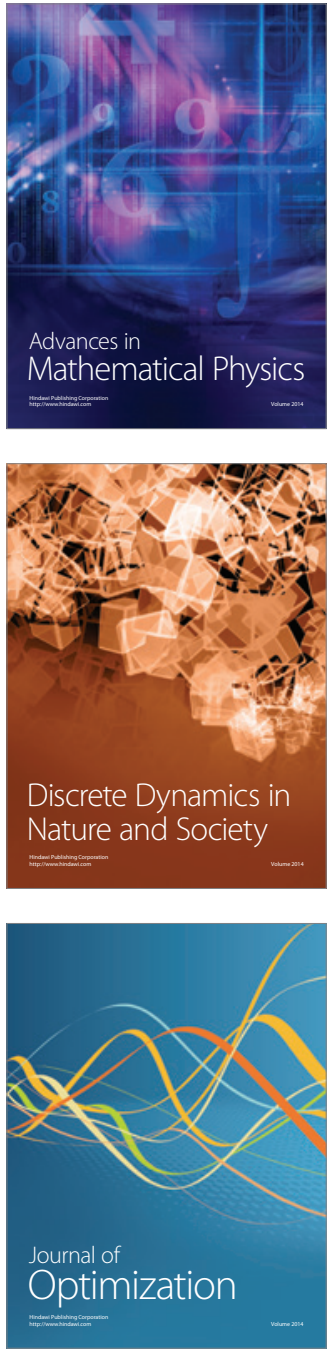